\title{
OPTIMIZATION OF POMEGRANATE PEEL FIBERS REINFORCED WITH POLYVINYL ALCOHOL BIOCOMPOSITE FILM USING RESPONSE SURFACE METHODOLOGY
}

\author{
G. Nandhavathy ${ }^{1}$, S. Periyar Selvam ${ }^{1, *}$, M. Mahesh Kumar \\ and E. Rotimi Sadiku \\ ${ }^{1}$ Department of Food Process Engineering, School of Bioengineering, SRM University, \\ Kattankulathur- 603203, Chennai, Tamilnadu, India \\ ${ }^{2}$ Department of Chemical, Metallurgical and Materials Engineering, Tshwane University of \\ Technology, CSIR Campus, Lynnwood ridge 0040, Republic of South Africa \\ *E-mail: periyar.india@gmail.com
}

\begin{abstract}
Biopolymers are considered as promising materials for replacing polythene bags in packaging industries. To reduce the non-degradable packaging wastes, biocomposite films were made from polyvinyl alcohol, reinforced with chemically treated pomegranate fibers and glycerol as plasticizer. The composition of the film was optimized using response surface methodology using fibre, pectin and polyvinyl alcohol concentrations as factors. The optimization was based on the influence of the factors on the responses of the biocomposite film. A rotatable central composite design was used. The responses considered were thickness, tensile strength and elongation. The optimized film had $0.15 \mathrm{~mm}$ thickness, $1.531 \mathrm{MPa}$ tensile strength and $44.01 \%$ elongation, made with $2.77 \%$ fibre, $1.23 \%$ pectin and $1.94 \%$ polyvinyl alcohol. Thus the optimized packaging film may be useful in the food packaging.

Keywords: Biocomposite film, pectin, pomegranate peel, polyvinyl alcohol, response surface methodology.
\end{abstract}

(C) RASĀYAN. All rights reserved

\section{INTRODUCTION}

Packaging plays a vital role in preserving the food materials. Packaging protects food between processing and usage by the consumer. The main aim of packaging is to reduce the food loss. Food loss is defined as the reduction in food mass that is palatable through the supply chain ${ }^{1}$. In order to reduce the usage of synthetic polymer, which originates from petroleum sources, are non-biodegradable. In order to maintain the environmental balance, more attention is paid to the packaging films that are made from natural sources in recent times, which are biodegradable. Biomaterial films can either be edible or inedible depending on the materials used, process of preparation and their application. Biopolymer materials used are often carbohydrates or proteins, which are extracted from plant, and animal sources. Punica granatum (pomegranate) belongs to the family Punicaceae that is a deciduous spreading shrub or small tree and has thorns. It is from Asia and cultivated throughout the Mediterranean region, China, India, South Africa, and America. It is either consumed freshly or as a beverage. Pomegranate has potential for the preventing cancer and can also be used for the treatment of inflammation and cancer; it shows an antiproliferative effect against human oral, breast, colon and prostate-cancer cell lines, inhibition of gastric ulceration, and an effect against oxidative damage in diabetic rats. Pomegranate peel is a byproduct obtained during pomegranate juice processing. Pomegranate peel has abundant amount of tannins, flavonoids, polyphenols and some anthocyanins as delphinidins, cyanidins ${ }^{2}$. Pomegranate peel components are found to have therapeutic properties. Antioxidant and antimicrobial properties of pomegranate peel in in vitro model systems have been reported ${ }^{3}$.

Response Surface Methodology (RSM) is a statistical tool, which is constructed on the fundamental principles of statistics, replication, randomization and duplication, which simplify the optimization by 
studying the mutual interactions among the variables. Type of error generating during responses will be the difference in the experiments. In physical experiments, inaccuracy may happen because of measurement errors while, in computer experiments, numerical noise is a result of incomplete convergence of iterative processes, round-off errors or the discrete representation of continuous physical phenomena ${ }^{4}$. The central composite design (CCD) of RSM is used for finding the accurate values, as it offers an advantage of comparing the variables of the responses for obtaining optimized value ${ }^{5}$. The real salt rejection ( $\mathrm{R}$ real) and maximum value of permeability of the PSF (polysulfones) membranes were predicted using response surface methodology's central composite design ${ }^{6}$.

\section{EXPERIMENTAL}

\section{Materials and methods}

The PVA, pectin, sodium hypochlorite, sodium hydroxide and the chemicals involved in the pretreatment of fibers were purchased from SRL (Sisco Research Laboratories Pvt. Ltd), Mumbai, India. Glycerol was purchased from Himedia, Mumbai, India.

\section{Methodology-}

The pomegranate peels were chopped to approximately $2 \mathrm{~cm}$ and they are dried and ground. The fibers were subjected to alkaline treatment using sodium hydroxide. The protocol of literature ${ }^{7}$ was followed with slight modification. The 20 grams of fiber was treated with $2 \%$ sodium hydroxide. Bleaching was done using $4 \%$ sodium hypochlorite and $2 \%$ sodium hydroxide and water. This step was repeated until the fibers became completely white. The fibers are then washed with water.

The bleached fibers are then treated with $65 \%$ sulphuric acid at $45^{\circ} \mathrm{C}$ with constant stirring of 35 to 40 minutes. During these treatments the lignin content in the fiber is reduced. Hydrolyzed samples were washed four times to reduce the acidity and filtered. The washed fibers were suspended in the water to obtain fiber suspension. This suspension is used for making films.

\section{Experimental design}

Design expert 9.0.7 was used for this study. When the responses of a process are affected by interaction of several independent variables involved in it, response surface methodology is used for optimization of the process $^{8}$. A standard rotatable central composite design was selected in which the experimental region ranged from -1.414 to +1.414 in terms of the coded independent variables. The levels of the independent variables, the concentration ratios of fibers $(0.1-3 \%)$, PVA $(1-3 \%)$ and pectin $(1-3 \%)$, a total of 20 trials were employed by the experimental design. The range chosen in the experimental design and the standardized concentration of pectin were decided, based on the preliminary studies conducted in the laboratory. Three replicates of each RSM trial were performed in order to eliminate error in the response data. The response variable is assumed to follow a second order quadratic model, which includes a linear model too. The model can be represented as given in equation (1):

$$
\mathrm{Y}=\beta_{0}+\sum_{\mathrm{i}=1}^{\mathrm{k}} \beta_{\mathrm{i}} \mathrm{X}_{\mathrm{i}}+\sum_{\mathrm{i}=1}^{\mathrm{k}} \beta_{\mathrm{ii}} \mathrm{X}^{2}+\sum_{\mathrm{i}}^{\mathrm{i}<j} \sum_{\mathrm{j}} \beta_{\mathrm{ij}} \mathrm{X}_{\mathrm{i}} \mathrm{X}_{\mathrm{j}}
$$

Where $\mathrm{Y}$ is the predicted response; $\mathrm{X}_{\mathrm{i}}$ and $\mathrm{X}_{\mathrm{j}}$ are the independent variables that influences the responses; $\beta_{0}$ is the offset term; $\beta_{\mathrm{i}}$ is the linear coefficient; $\beta_{\mathrm{ii}}$ is the quadratic coefficient and $\beta_{\mathrm{ij}}$ is the interaction coefficient.

PVA and fiber were chosen as the variable factor and pectin being the constant factor. By altering the concentration of the different components, the films were casted on a trial-error basis.

\section{Film preparation}

Films were prepared using casting method as performed in literature ${ }^{9}$. Polyvinyl alcohol (PVA) was used as the base polymer for the preparation of biocomposite. Glycerol was used as a plasticizer. Pectin is used as a thickening agent and emulsifier. Pectin (1-3\%) was dissolved along with $0.1-3 \%$ treated pomegranate fibers and with 1 - 3\% PVA crystals. The solution was prepared using distilled water and is to be boiled for 5 minutes in order to dissolve pectin along with other constituents. Glycerol was then added to the 
solution. The solution is then poured into a $9 \mathrm{~cm}$ Petridish. It is then kept in hot air oven for drying at $55^{\circ} \mathrm{C}$ for 4 to 5 hours. All the 20 trials were performed in triplicates to reduce error. After drying the films were then peeled off the plate's surface.

\section{Measurement of responses}

The responses considered for the study were thickness ( $\mathrm{mm})$, tensile strength (MPa) and elongation (\%). Thickness was measured using digital Vernier calipers. Three replicates sample readings were taken for each sample and their average was considered. Tensile strength (TS) and elongation were measured as per ASTM D882 using a digital tensile testing machine (Instron 4204 - G.B), with a maximum capacity of $2500 \mathrm{~N}$ and an accuracy of $\pm 1 \%$.

\section{Optimization of film}

The response values were analyzed by regression analysis using backward elimination method for the fitting of responses. Optimization of the film concentration was dome taking all the responses for their desired optimum values. Analysis of regression was used for generating second order coefficients. Evaluation of model fit for each response was done by considering to the $\mathrm{R}^{2}$ value and the analysis of variance.

\section{RESULTS AND DISCUSSION}

\section{Measurement and analysis of responses}

Biopolymer materials will undergo a lot of stress while use; in order to determine the sustainability of the film tensile strength is checked. The responses chosen i.e., thickness, tensile strength and elongation, were obtained for all the 20 trials and the tabulation is as shown in Table-1.

Table-1: Response values of the designed experimental runs

\begin{tabular}{c|c|c|c}
\hline Run & Ti Thickness $(\mathrm{mm})$ & $\begin{array}{c}\text { Tensile Strength } \\
(\mathrm{MPa})\end{array}$ & Elongation (\%) \\
\hline 1 & $0.09 \pm 0.01$ & $2.588 \pm 0.58$ & $80.72 \pm 0.85$ \\
\hline 2 & 0 & 0 & 0 \\
\hline 3 & $0.11 \pm 0.01$ & $0.357 \pm 0.08$ & $7.5 \pm 0.55$ \\
\hline 4 & $0.17 \pm 0.08$ & $0.245 \pm 0.01$ & $49.8 \pm 0.98$ \\
\hline 5 & $0.12 \pm 0.01$ & $0.313 \pm 0.01$ & $22.2 \pm 0.98$ \\
\hline 6 & $0.11 \pm 0.04$ & $2.43 \pm 0.89$ & $73.41 \pm 0.98$ \\
\hline 7 & $0.10 \pm 0.03$ & $0.2 \pm 0.014$ & $10.6 \pm 0.42$ \\
\hline 8 & $0.17 \pm 0.02$ & $0.735 \pm 0.17$ & $4.44 \pm 0.19$ \\
\hline 9 & $0.11 \pm 0.03$ & $1.688 \pm 0.33$ & $4.5 \pm 0.57$ \\
\hline 10 & $0.17 \pm 0.03$ & $0.432 \pm 0.18$ & $23.4 \pm 0.84$ \\
\hline 11 & $0.10 \pm 0.04$ & $0.521 \pm 0.1$ & $10.5 \pm 0.28$ \\
\hline 12 & $0.09 \pm 0.003$ & $0.25 \pm 0.08$ & $12.5 \pm 1.83$ \\
\hline 13 & $0.08 \pm 0.006$ & $0.56 \pm 0.18$ & $24.11 \pm 1.25$ \\
\hline 14 & $0.05 \pm 0.001$ & $2.02 \pm 0.09$ & $32.75 \pm 0.21$ \\
\hline 15 & $0.08 \pm 0$ & $0.2080 \pm 0.08$ & $10 \pm 0.98$ \\
\hline 16 & $0.03 \pm 0.002$ & $0.977 \pm 0.02$ & $39.01 \pm 0.12$ \\
\hline 17 & $0.18 \pm 0.04$ & $0.491 \pm 0.18$ & $19.51 \pm 0.86$ \\
\hline 18 & $0.05 \pm 0.003$ & $0.179 \pm 0.03$ & $2.5 \pm 0.83$ \\
\hline 19 & $0.25 \pm 0.08$ & $2.33 \pm 0.96$ & $42.58 \pm 0.96$ \\
\hline 20 & $0.06 \pm 0.04$ & $2.414 \pm 0.52$ & $65.58 \pm 0.60$ \\
\hline
\end{tabular}




\section{Model fitting}

As per the sum of squares of sequential model, the highest order polynomial in the supplementary terms being selected is also significant. This was followed by regression analysis with the help of ANOVA.

\section{Regression analysis}

Regression analysis was performed with the help of ANOVA. The $\mathrm{P}$ value (prob $>\mathrm{F}$ ) are all lesser than 0.05 which favors fitting of the model. Also all the 'Lack of Fit' values were non-significant in relation to the pure error. The R squared value for thickness, tensile strength and elongation were $0.6261,0.8443$ and 0.7469 respectively. An adequate precision ratio greater than 4 is desired and the values for thickness, tensile strength and elongation were 9.629, 5.799 and 4.647 respectively, which indicates an adequate signal in all the responses. Hence it is concluded that the chosen model fits well for all the three responses.

\section{Tensile strength and elongation}

The addition of pomegranate peels to the pectin film has influenced the film properties. The maximum tensile strength was $2.588 \mathrm{Mpa}$, which was lower than the aloefiber reinforced corn starch films ${ }^{10}$. This may be due fragility of the films while preparation of analysis, as cracks in the end of the film will induce breaking of film. The decrease in tensile strength may also be due to decrease in intermolecular forces between adjacent molecules. Plasticizer addition significantly induced the elasticity property of the film, the maximum elongation value was $80.72 \%$ which was more than the values obtained for sorbitol plasticized whey protein isolate films ${ }^{11}$.

\section{Experimental design}

The 3-D surface plot shown in the Fig.-1 indicates the effect of PVA, fibre and pectin on thickness response. As the concentration of PVA and fibre increases the thickness of the film increases. The presence of pectin indicates the overall increase in the thickness of the film.

The 3-D surface plot shown in the Fig.-2 indicates the effect of PVA, fibre and pectin on tensile strength response. It is observed that the tensile strength increases with the increase in the concentration of PVA, fibre and pectin, however decreases at the extreme values of all the factors.

The 3-D surface plot shown in the Fig.-3 indicates the effect of PVA, fibre and pectin on elongation response. It is observed that the elongation increases with the increase in the concentration of PVA, fibre and pectin, however decreases at the extreme values of all the factors.

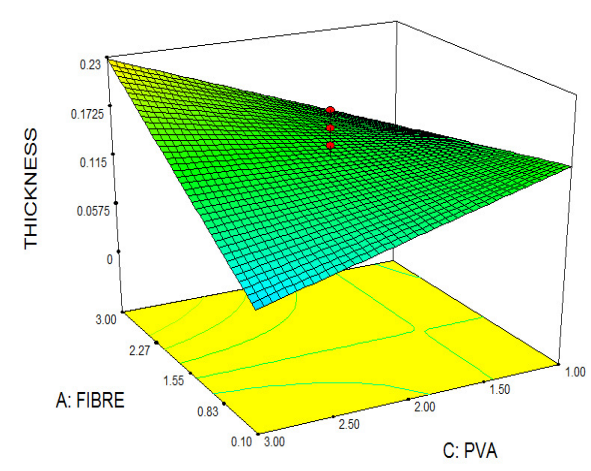

(a)

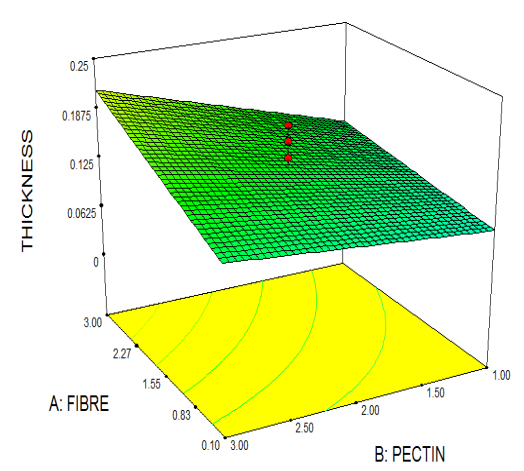

(b)

Fig.-1: 3-D surface plot effect on thickness (a) fibre vs PVA (b) fibre vs pectin

The 3-D surface plots indicate increase in the fibre, pectin and PVA content increased the effect on thickness, tensile strength and elongation. The surface plots were similar to those observed in the literature $^{12}$, with maximal and minimal values. The lacks of fit were non-significant in relation to pure 
error and also the expected values were similar to observed values, this signifies that the experimental data was validated by response surface methodology, which was similar to the results reported in literature ${ }^{13}$.

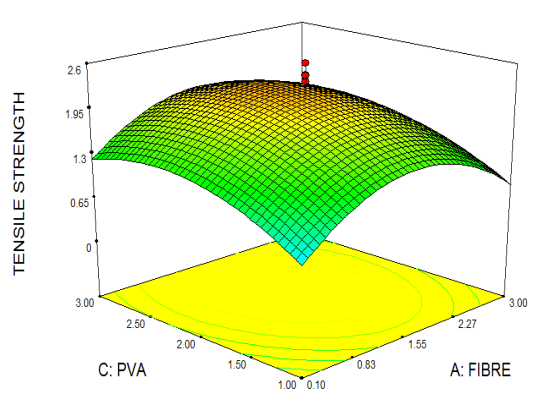

(a)

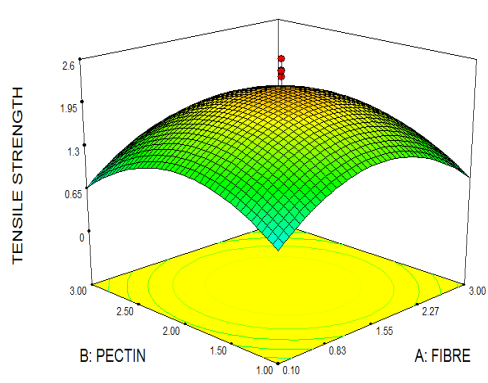

(b)

Fig.-2: 3-D surface plot effect on tensile strength (a) fibre vs PVA (b) fibre vs pectin

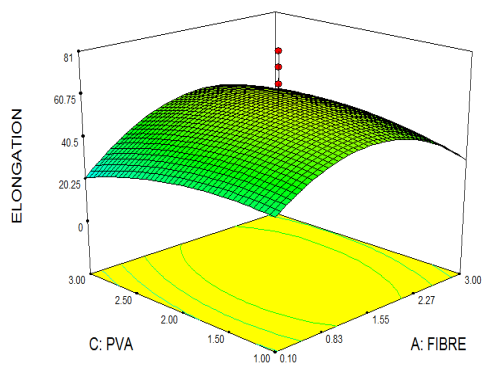

(a)

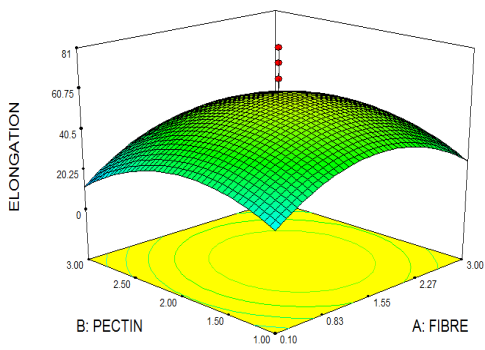

(b)

Fig.-3: 3-D surface plot effect on elongation (a) fibre vs PVA (b) fibre vs pectin

\section{Optimization of the film composition}

Numerical and graphical optimizations were done for the design. Tensile strength was considered as higher target value for the optimum strength, while thickness and elongation are considered near target value. Both numerical and graphical optimizations were in good agreement with each other. The response values predicted were determined experimentally, by forming films with the concentration mentioned. When measured all the three responses were found to be in agreement with the predicted responses from the software. The optimized concentration values are as shown in Table- 2 .

Table-2: Optimized solution predicted by numerical optimization procedure

\begin{tabular}{c|c|c|c|c|c|c|c}
\hline No. & $\begin{array}{c}\text { Fibre } \\
(\%)\end{array}$ & $\begin{array}{c}\text { Pectin } \\
(\%)\end{array}$ & $\begin{array}{c}\text { PVA } \\
(\%)\end{array}$ & $\begin{array}{c}\text { Thickness } \\
(\mathrm{mm})\end{array}$ & $\begin{array}{c}\text { Tensile } \\
\text { strength } \\
(\mathrm{MPa})\end{array}$ & $\begin{array}{c}\text { Elongation } \\
(\%)\end{array}$ & Desirability \\
\hline 1. & 2.77 & 1.23 & 1.94 & 0.15 & 1.531 & 44.01 & 1.000 \\
\hline
\end{tabular}

\section{Film microstructure}

The films were quite yellow in color and translucent. Scanning Electron Microscopy (SEM) analysis provides information regarding morphology, pore and size geometry of the film. SEM image 500X magnification is represented in the Fig.-4. The film was continuous without any discontinuities as observed in literature ${ }^{14}$, in pectin films of similar concentrations. The smooth surface of the film is due to alkalization, which destroyed the rough surface of the fibers. The bio-composite film exhibited smooth and homogeneous morphology without any cracks with no sign of phase separation and also the film has fibril structure, which indicated the complete miscibility between biopolymers and plasticizers. 


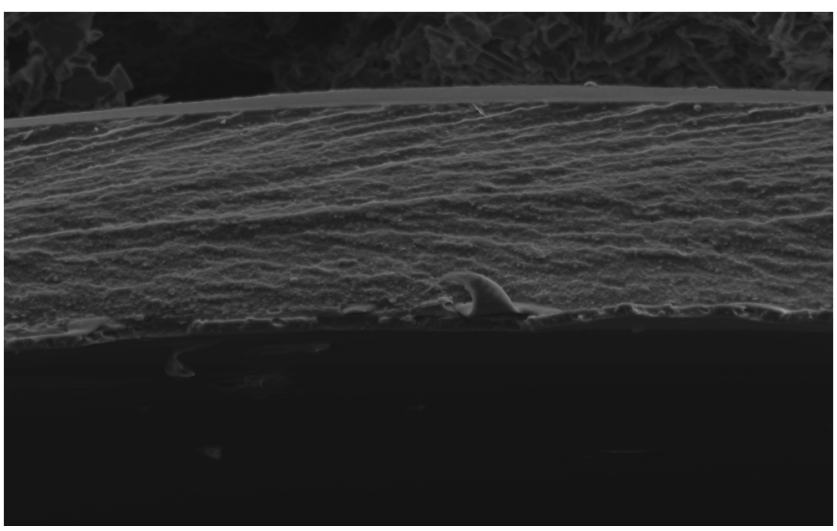

Fig.-4: SEM image of optimized film

\section{TG/DTA Analysis}

The TG/DTA analysis was done and the graph was obtained as shown in Fig.-5. From the TG graph it concluded that the film started to melt around $160^{\circ} \mathrm{C}$ and complete degradation of the film is around $800^{\circ} \mathrm{C}$.

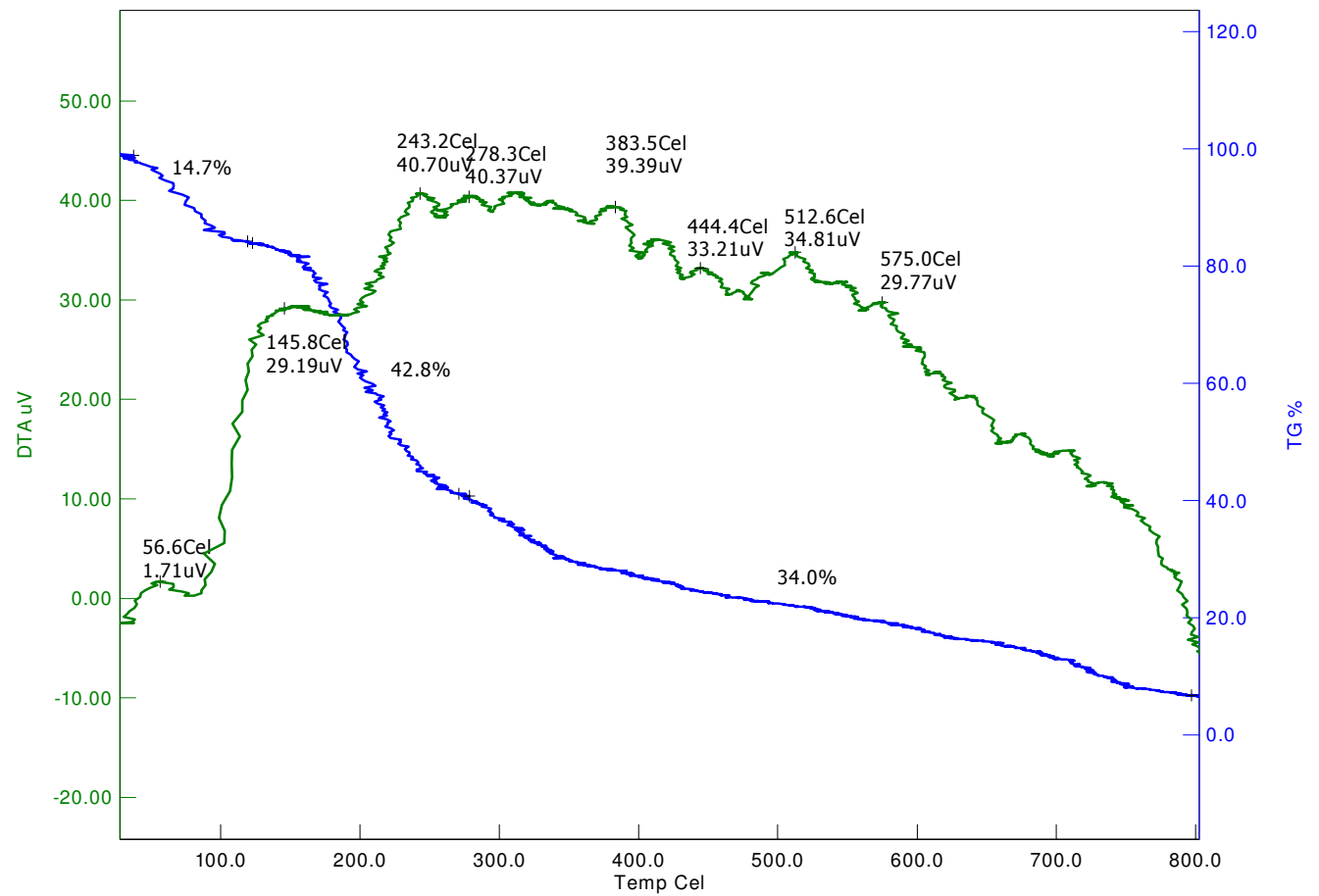

Fig.-5: TG/DTA graph of optimized film

The DTA curve shows that, the endothermic reaction reaches its peak below $180^{\circ} \mathrm{C}$ and exothermic reaction is observed to have its peak reaction at $243^{\circ} \mathrm{C}$, which indicates the degradation of all lignin and other cellulosic materials in the fiber. The endothermic reaction is because of the water loss during the process of crystallization, which destroys the compound partially, that results increase in surface area, and promotes further thermal decomposition easier.

For the optimized film the initial degradation starts around $100^{\circ} \mathrm{C}$, which indicates the evaporation of moisture, thermal degradation peak was observed around $250^{\circ} \mathrm{C}$ and the loss of mass was around $42.8 \%$, which is greater than the thermal degradation of natural pectin films which was around $219^{\circ} \mathrm{C}$ as observed in literature ${ }^{15}$, this indicates the increase in the thermal stability of the pomegranate peel fibres reinforced with polyvinyl alcohol biocomposite film, which may be due to structural reorganization of polymers 
occurred during alkaline treatments of fibres ${ }^{16}$. In the final degradation phase, $34 \%$ of the residual mass was completely degraded around $800^{\circ} \mathrm{C}$, which indicates that the sample has high thermal stability.

DTA profiles show the endothermic peaks are at $56^{\circ} \mathrm{C}$ and $145^{\circ} \mathrm{C}$ and the exothermic peaks were observed between $243^{\circ} \mathrm{C}$ and $575^{\circ} \mathrm{C}$, which indicates that is the temperature for thermal depolymerization of pectin chain ${ }^{17}$.

\section{CONCLUSION}

Pomegranate peel fibers reinforced polyvinyl alcohol biocomposite film was developed successfully by casting technique after treating raw fibres with alkali, bleaching agent and acid. It exhibited good film forming property. The study begun with trial and error to find out appropriate PVA and pectin range. The range was fed into RSM to obtain trails. The films were prepared according to that and were measured for their responses, which were then analyzed to find out the optimized film concentration with maximum desirability. The film was optimized at $2.77 \%$ fibre content, $1.23 \%$ Pectin and $1.94 \%$ PVA. The predicted values were in agreement with the experimental values. The fibre loading enhanced the mechanical property of the film with high tensile strength of $2.588 \mathrm{Mpa}$. This suggests that the pomegranate peels can act as good reinforcing agent.

\section{ACKNOWLEDGMENT}

The authors are greatly acknowledged the funding agency; Department of Science and Technology (DST), India and the National Research Foundation (NRF), South Africa in the Bilateral Research Collaboration Program (DST/INT/South Africa/P-07/2014). The authors express their thanks to Prof. C. Muthamizchelvan, Director (Engineering and Technology), Dr. M. Vairamani, Dean School of Bioengineering, SRM University for their cordial support. In addition, the authors express their special thanks to Dr. Kingsley Jeba Singh, Dean School of Mechanical Engineering, SRM University, for providing the facilities.

\section{REFERENCES}

1. J. Gustavsson, Global food losses and food waste. (FAO, 2011). http://www.fao.org/docrep/014/mb060e/mb060e00.pdf.

2. Y. Li, C. Guo, J. Yang, J. Wei, J. Xu and S. Cheng, Food Chemistry, 96, 254(2006).

3. M. Reddy, S. Gupta, M. Jacob, S. Khan and D. Ferreira, Planta Medica, 73, 461(2007).

4. https://pdfs.semanticscholar.org/35a0/7811751f8c3e257b0b1eb2e3679412d2d5b4.pdf.

5. Y. Garnida, Y. Taufik and T. Widiantara, Rasayan Journal of Chemistry, 9(4), 762(2016).

6. L. Y. Ng, C. P. Leo and A. W. Mohammad, Journal of Applied Polymer Science, 121, 1804(2011).

7. E. Dinand, H. Chanzy and R.M. Vignon, Food Hydrocolloids, 13, 275(1999).

8. R.L. Mason, F.G. Richard and L.H. James, Designs and Analyses for Fitting Response Surfaces, Wiley online library (2003).

9. C.A. Campos, L.N. Gerschenson and S.K. Flores, Food and Bioprocess Technology, 4, 849(2011).

10. K. Anulakshmi and S. Periyar selvam, International Journal of Chem Tech Research, 7, 2970 (2015).

11. M.A. Rojas-Grau, R.J. Avena-Bustillos, C. Olsen, M. Friedman, P.R. Henika, O. Mart in-Belloso, Z. Pan and T.H. Mchugh, Journal of Food Engineering, 81, 634(2007).

12. H.J. Rao, P. King and Y. P. Kumar, Rasayan Journal of Chemistry, 9 (2), 254(2016).

13. R. Kumar, P. Chanalia, D. Gandhi, S. Dhanda and Rakhi, World Applied Sciences Journal, 34, 704(2016).

14. S. Galus, A. Turska and A. Lenart, Czech Journal of Food Sciences, 30, 446(2012).

15. J.F.A. Souto-Maior, A.V. Reis, L.N. Pedreiro and O.A. Cavalcanti, Polymer International, 59, 127(2010).

16. F.M. Carbinatto, A.D. de Castro, B.S.F. Cury, A. Magalhães and R.C. Evangelista, International Journal of Pharmaceutics, 423, 281(2012).

17. L. Shi and S. Gunasekaran, Nanoscale Research Letters, 3, 491(2008).

[RJC-1724/2017] 